\title{
O desenvolvimento da China e suas consequências globais
}

XiAOQIn Ding

Resumo: O desenvolvimento econômico e social da China vem merecendo atenção mundial. Apesar da recente crise, a economia chinesa permanece forte e se tornou o motor da recuperação global. Com esse artigo, analiso a influência e a participação chinesa nos mercados africanos e latino-americanos.

\section{Palavras-chave:}

Desenvolvimento; Economia Mundial; China.

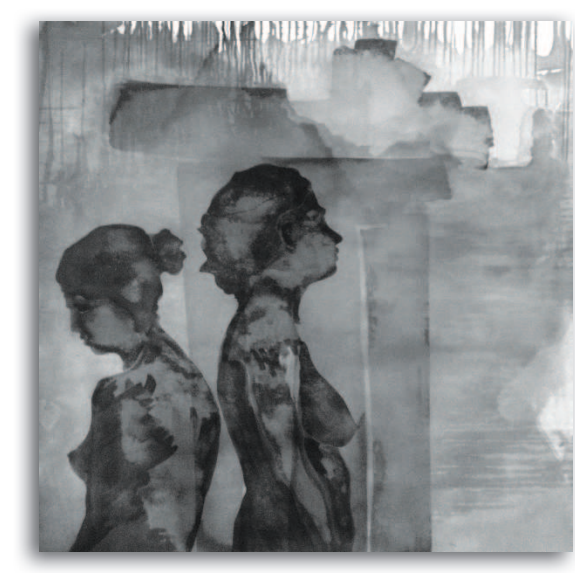

China's economic development and its global consequences

\section{XIaogin Ding}

Ph.D, professor e diretor-assistente do Marxism Research Institute e do Centro de Economia da Universidade de Shangai. Pesquisador da Academia Chinesa de Ciências Sociais, e do Centro Asiático da Universidade de Harvard. Secretáriogeral da World Association for Political Economy e editor executivo da World Review of Political EConomy (WRPE).

Abstract: The economic and social development of China has merited worldwide attention. Despite the recent crisis, the Chinese economy remains strong and has become the engine of global recovery. This article analyzes Chinese influence and participation in markets in Africa and Latin America

Keywords: Development; World Economy; China. 


\section{INTRODUÇÃO}

As grandes conquistas da China no desenvolvimento econômico e social têm sido o foco da atenção mundial. Neste âmbito, em 2010, o PIB chinês foi o segundo maior do mundo, logo atrás dos Estados Unidos. O volume total de exportações e importações também foi o terceiro, depois dos Estados Unidos e da Alemanha. Ao mesmo tempo, a China tem a maior reserva de moeda estrangeira do mundo. Em especial, depois da reforma e abertura chinesas, a média de crescimento do PIB alcançou 9,6\% nos últimos trinta anos, índice sem igual no tocante à velocidade e duração do desenvolvimento econômico.

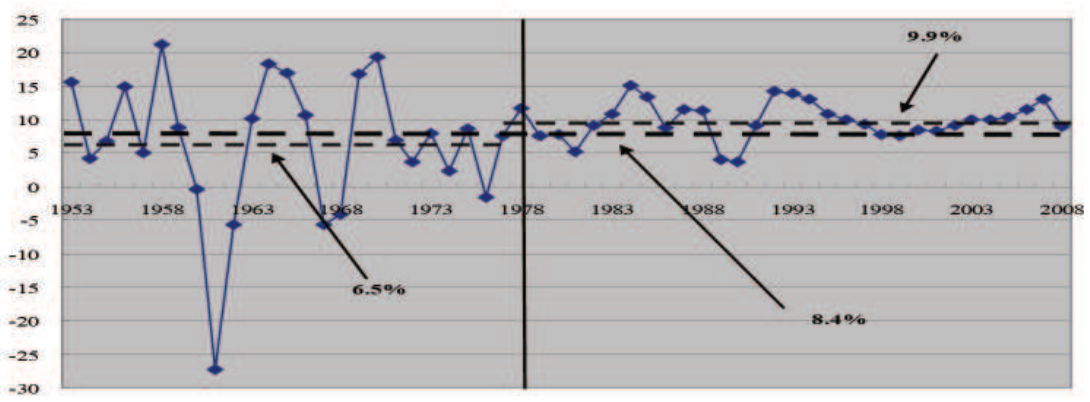

\section{Gráfico 1 - Taxa de crescimento do PIB da China (1953-2008)}

Com o rápido crescimento econômico da China, recursos domésticos e mercados limitados são incapazes de atingir suas necessidades de desenvolvimento econômico. Enquanto acelera a transformação do seu modo de desenvolvimento econômico e o ajuste da sua estrutura industrial, a China está constantemente acelerando sua expansão econômica no exterior, aumentando regularmente seu nível de abertura econômica, e gradualmente estabelecendo um padrão de benefício mútuo no relacionamento econômico internacional. Nesta ótica, o desenvolvimento rápido e constante do mercado de serviços, o grande avanço no ajuste estrutural do comércio exterior, a consolidação constante das vantagens comparativas tradicionais e o surgimento de novas vantagens da competição internacional fizeram da China um dos gigantes do investimento estrangeiro. A China insiste em uma postura 
de "entrada" e "saída" e tem conseguido progresso generalizado em investimentos estrangeiros diretos. Além disto, a cooperação econômica internacional da China mantém um ritmo acelerado de crescimento, o nível de contratação de projetos no exterior está melhorando, a estrutura e os campos de comércio exterior estão se otimizando continuamente, a cooperação da mão-de-obra no estrangeiro cresce regularmente e a ordem do mercado tem sido ainda mais regularizada.

Sob as circunstâncias internacionais de lenta recuperação nas maiores economias do mundo; a disseminação da crise da dívida soberana europeia; a situação cada vez mais séria dos conflitos regionais; o crescente protecionismo no comércio internacional e a ameaça de inflação global, economias emergentes, representadas pelos países do BRICS, têm, em geral, mantido seu forte crescimento econômico. Desse modo, é de grande importância estratégica que a China desenvolva sua economia no exterior e que estabeleça uma ordem de relacionamento econômico internacional aberta, compatível e justa com mercados emergentes e países em desenvolvimento, ao seguir o princípio básico do benefício mútuo e um cenário de cooperação recíproca.

Este artigo descreverá a extensão e evolução da presença comercial chinesa e o fluxo dos seus investimentos diretos, particularmente na América Latina e na África, analisando, então, seus efeitos.

\section{EXPANSÃO ECONÔMICA DA CHINA NO EXTERIOR}

\subsection{Comércio exterior}

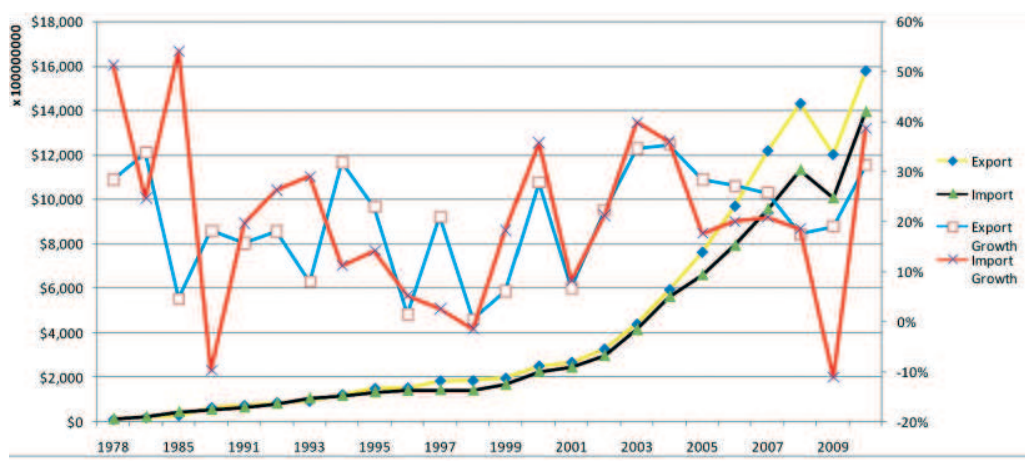

Gráfico 2 - Exportações e importações chinesas por mercadoria e seus níveis de crescimento (1980-2010) 
Desde a reforma e abertura chinesas, o comércio das suas mercadorias tem mantido um crescimento rápido e regular. A China se tornou o maior exportador mundial (U\$ 1.577,9 bilhões em 2010) e o segundo país em comércio (U\$2.872,8 bilhões em 2010), com uma taxa de crescimento anual de 17,2\% para as exportações e a proporção de exportações mundiais avaliada em 8,7\%; e, ainda, uma taxa de crescimento de importações de 16,4\% e a proporção de importações mundiais em torno de 6,7\%. Como evidenciado, a estrutura de importação e exportação chinesas tem sido constantemente otimizada, com a predominância de produtos manufaturados, mercados importadores e exportadores distribuídos de maneira diversa e tendo países e regiões desenvolvidas como seus maiores parceiros comerciais.

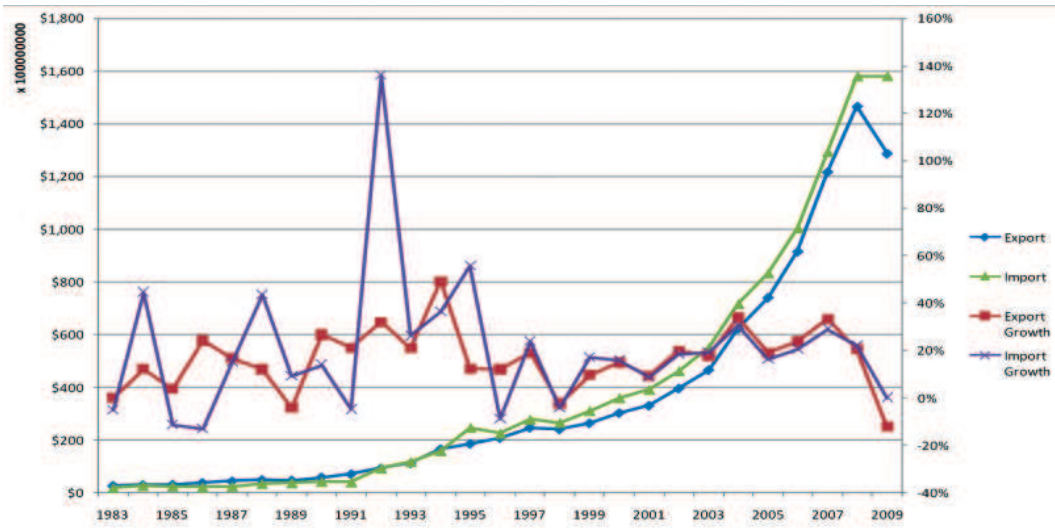

\section{Gráfico 3 - Importações e exportações chinesas de serviços e suas taxas de crescimento (1982-2009)}

Como podemos ver pelo Gráfico 3 - exceto em 2009, por causa da crise financeira internacional -, o comércio de serviços chinês tem mantido, em geral, um crescimento acelerado, com suas exportações de serviços atingindo o quarto lugar mundial e as importações o terceiro lugar. O comércio chinês de serviços corresponde a 11,5\% do seu comércio exterior, mas, ao contrário do grande superávit no comércio de mercadorias, o déficit do comércio de serviços tem aumentado através dos anos e atingiu cerca de U\$ 29,5 bilhões em 2009. Em termos de estrutura, o comércio 
tradicional de serviços ainda corresponde à maioria, e indústrias emergentes do comércio de serviços estão se desenvolvendo rapidamente. Em sua maior parte, os mercados de importação e exportação estão concentrados em Hong Kong, Estados Unidos e países da União Europeia.

\subsection{Fluxo de investimentos estrangeiros diretos}

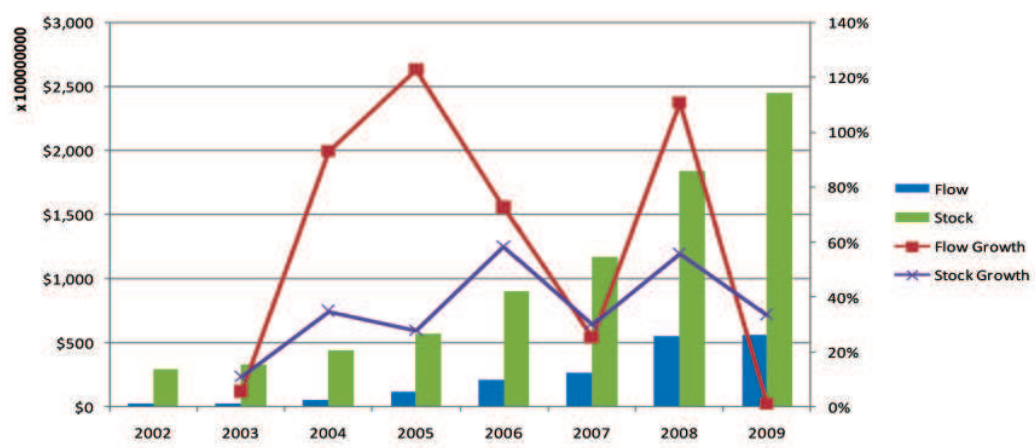

Gráfico 4 - O fluxo e estoque de investimentos estrangeiros diretos na China e suas taxas de crescimento (2003-2009)

De 2003 a 2009, a taxa de crescimento anual do fluxo de investimentos estrangeiros diretos (IED) chinês atingiu 64,6\% e a taxa de estoque 39,6\%; em 2009, o IED chinês foi responsável por 5,1\% do fluxo e 1,3\% do estoque de IED global, alcançando a quinta colocação mundial por fluxo e a primeira entre os países em desenvolvimento. Quanto à distribuição regional, o investimento estrangeiro daqule país está concentrado principalmente na Ásia e América Latina, que correspondem a cerca de 90\% do investimento estrangeiro total da China. Além disto, parte significativa do investimento estrangeiro chinês é para aumentar a participação de capital e reinvestir os lucros do período. 


\subsection{Cooperação econômica}

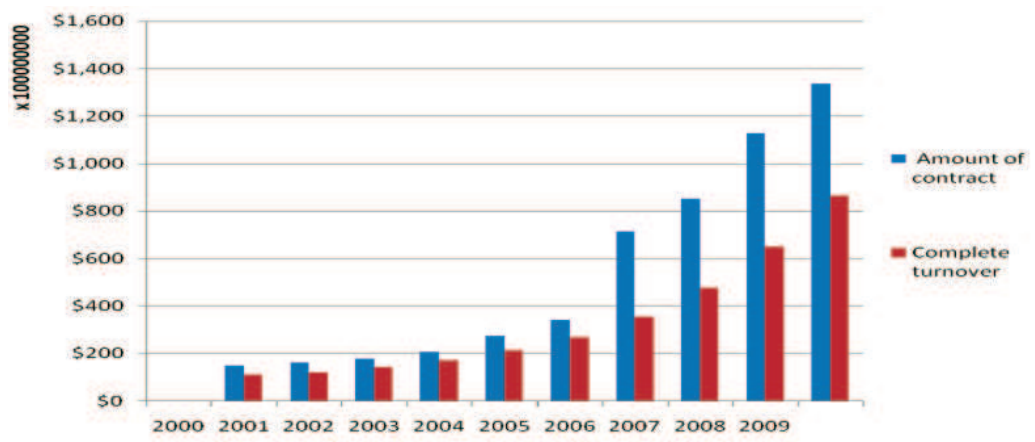

Gráfico 5 - Cooperação econômica chinesa (contratação de projetos, cooperação de mão-de-obra) e suas taxas de crescimento

De 2000 a 2009, a taxa de crescimento do volume de negócios contratados da cooperação econômica estrangeira chinesa chegou a 27,6\% e a taxa de crescimento do volume de negócios completados 25,4\%. A Ásia e a África foram responsáveis por cerca de 80\% do total de cooperação econômica estrangeira da China, sendo as regiões com maior participação na cooperação econômica estrangeira chinesa. Em 2009, o volume de negócios contratados da cooperação econômica estrangeira chinesa totalizou U\$133,68 bilhões e o volume de negócios completados foi de U\$ 86,62 bilhões.

\section{EXPANSÃO ECONÔMICA CHINESA NA ÁFRICA E AMÉRICA LATINA}

\subsection{O status quo da expansão econômica chinesa na América Latina}

Quadro 1 - O volume total das importações e exportações China-América Latina e suas proporções

\begin{tabular}{|c|c|c|}
\hline ANo & Volume (BILHões U\$ & Proporção (\%) \\
\hline 2000 & 12,6 & 2,7 \\
\hline 2001 & 14,9 & 2,9 \\
\hline
\end{tabular}


Quadro 1 - O volume total das importações e exportações China-América Latina e suas proporções

\begin{tabular}{|c|c|c|}
\hline ANo & VOLUMe (BILHÕES U\$) & PROPORÇÃo (\%) \\
\hline 2002 & 17,8 & 2,9 \\
\hline 2003 & 26,8 & 3,1 \\
\hline 2004 & 40,0 & 3,5 \\
\hline 2005 & 50,5 & 3,5 \\
\hline 2006 & 70,2 & 4,0 \\
\hline 2007 & 102,7 & 4,7 \\
\hline 2008 & 143,4 & 5,6 \\
\hline 2009 & 121,9 & 5,5 \\
\hline
\end{tabular}

Fonte: China Statistical Yearbook (2000-2010).

No período de 2000 a 2009, a taxa de crescimento anual do volume de comércio China-América Latina alcançou 28,7\%, bem maior do que a taxa de comércio exterior da China durante o mesmo período: 18,6\%. A proporção do volume total de comércio bilateral nas importações e exportações chinesas está aumentando constantemente. Desse modo, a América Latina está se tornando um parceiro comercial cada vez mais importante, com o Brasil, o Chile e o México no topo da lista. Ademais, aquele país tornou-se o terceiro maior parceiro comercial da América Latina, enquanto a região é a que apresenta o crescimento mais rápido de exportações para o mencionado país.

Contudo, em seu comércio com a América Latina, a China fica em déficit durante todo o ano, em decorrência das grandes quantidades de importações de produtos como minério de ferro, minério de cobre, petróleo e produtos agrícolas como óleo de soja. Ao mesmo tempo, exporta produtos mecânicos e eletrônicos e outros produtos industriais para a região.

Em geral, a escala de comércio China-América Latina está aumentando e a estrutura deste comércio está em constante otimização. Assim, a importância da região no comércio exterior chinês cresce junto com o relacionamento comercial entre os dois atores. 
Quadro 2 - O fluxo de escoamento dos Investimentos Estrangeiros Diretos entre China e América Latina, e suas proporções

\begin{tabular}{|c|c|c|}
\hline ANo & Volume (BILHÕES U\$ & ProporÇão (\%) \\
\hline 2003 & 1,04 & 36,0 \\
\hline 2004 & 1,76 & 32,0 \\
\hline 2005 & 6,47 & 53,0 \\
\hline 2006 & 8,47 & 48,0 \\
\hline 2007 & 4,90 & 19,0 \\
\hline 2008 & 3,68 & 7,0 \\
\hline 2009 & 7,33 & 13,0 \\
\hline
\end{tabular}

Fonte: Relatório oficial do fluxo de IED da China (2003-2009).

No período 2003-2009, a taxa de crescimento anual dos investimentos estrangeiros diretos da China para a América Latina atingiu 38,5\%, de modo que a América Latina sempre foi a segunda região em recebimento de investimentos estrangeiros diretos. Como maiores recebedores, permanecem as Ilhas Caimãs e as Ilhas Virgens Britânicas. Sem levar em consideração estas duas ilhas, o fluxo de investimento direto chinês para a América Latina em 2009 foi de apenas U\$ 350 milhões, ou seja, somente 0,6\% do fluxo de escoamento de IED da China, sendo Brasil e Venezuela os maiores beneficiários do investimento estrangeiro direto daquele país. Além disto, exceto por alguns anos, o estoque de IED da China na América Latina permanece em crescimento regular, com o ritmo de crescimento anual atingindo 37\%. E, mais, exceto pelas Ilhas Caimãs e as Ilhas Virgens Britânicas, Brasil, Peru e Venezuela correspondem à maior proporção do IED da China.

De modo geral, o investimento estrangeiro direto da China na América Latina ainda está em seu estágio inicial, com forte tendência de crescimento e investimentos principalmente em recursos como minério de ferro, de cobre e petróleo. 
Quadro 3 - O volume de contratação de projetos, cooperação de mão-de-obra e consultoria de projetos entre China e América Latina e suas proporções

\begin{tabular}{|c|c|c|}
\hline ANo & Volume (BILHÕES U\$ & ProporçÃo (\%) \\
\hline 2005 & 1,47 & 5,5 \\
\hline 2006 & 1,97 & 5,6 \\
\hline 2007 & 2,92 & 6,1 \\
\hline 2008 & 3,05 & 4,7 \\
\hline 2009 & 3,68 & 4,2 \\
\hline
\end{tabular}

Fonte: China Statistical Yearbook (2005-2010).

No período 2005-2009, a taxa de crescimento anual do volume de contratações de projetos, cooperação de mão-de-obra e consultoria de projetos com a América Latina alcançou 25,7\%, menor que a taxa de cooperação econômica estrangeira global da China durante o mesmo período. Além do mais, sua proporção no volume total de cooperação econômica internacional chinês é relativamente baixo e passou por algumas flutuações leves. Em 2009, o volume de contratação de projetos representou mais de $99 \%$ dos três, enquanto a cooperação de mão-de-obra e consultoria de projetos correspondeu a menos de 1\%. Brasil e Venezuela são os dois maiores parceiros chineses em cooperação econômica na América Latina, o que representou 55,4\% da cooperação econômica internacional da China.

Em termos gerais, sua escala de cooperação econômica com a América Latina é relativamente baixa e concentrada sobretudo na contratação de projetos.

\subsection{O status quo da expansão econômica chinesa na África}

Quadro 4 - O volume do comércio China-África e suas proporções no total do comércio internacional chinês

\begin{tabular}{|c|c|c|}
\hline ANo & Volume (BILHÕes U\$) & Proporção (\%) \\
\hline 2000 & 10,60 & 2,2 \\
\hline 2001 & 10,80 & 2,1 \\
\hline 2002 & 12,39 & 2,0 \\
\hline
\end{tabular}

Continua 
Quadro 4 - 0 volume do comércio China-África e suas proporções no total do comércio internacional chinês

\begin{tabular}{|c|c|c|}
\hline ANo & Volume (BILHÕEs U\$\$) & ProporçÃo (\%) \\
\hline 2003 & 18,54 & 2,2 \\
\hline 2004 & 29,46 & 2,6 \\
\hline 2005 & 39,74 & 2,8 \\
\hline 2006 & 55,46 & 3,2 \\
\hline 2007 & 73,66 & 3,4 \\
\hline 2008 & 107,21 & 4,2 \\
\hline 2009 & 91,06 & 4,1 \\
\hline
\end{tabular}

Fonte: China Statistical Yearbook (2000-2010).

De 2000 a 2009, o volume total de comércio entre China e África aumentou de U\$ 10,6 bilhões para U\$ 91,06 bilhões, com uma taxa de crescimento anual de $27 \%$. A proporção do volume total do referido comércio no total de importações e exportações chinesas manteve um crescimento regular, logo, a África está gradualmente se tornando um dos parceiros comerciais mais importantes da China. Entre estes, Angola e África do Sul são seus maiores parceiros comerciais. Enquanto isso, a China ultrapassou os EUA e se tornou o segundo maior parceiro comercial africano, depois da União Europeia. No comércio com a África, a China sempre está em déficit, em virtude das grandes quantidades de importação de recursos como petróleo, ao passo em que exporta produtos industriais.

No geral, com o aperfeiçoamento de um novo tipo de parceria estratégica entre China e África, o comércio entre os dois possui grande potencial de crescimento.

Quadro 5 - O fluxo de escoamento de IED entre China e África e seus proporções no total de escoamento do IED chinês

\begin{tabular}{|c|c|c|}
\hline ANo & Volume (BILHÕEs U\$) & ProporçÃo (\%) \\
\hline 2003 & 0,08 & 3,0 \\
\hline 2004 & 0,32 & 6,0 \\
\hline 2005 & 0,40 & 3,0 \\
\hline
\end{tabular}

Continua 
Quadro 5 - O fluxo de escoamento de IED entre China e África e suas proporções no total de escoamento do IED chinês

\begin{tabular}{|c|c|c|}
\hline ANo & Volume (BILHÕEs U\$) & Proporção (\%) \\
\hline 2006 & 0,52 & 3,0 \\
\hline 2007 & 1,57 & 6,0 \\
\hline 2008 & 5,49 & 10,0 \\
\hline 2009 & 1,44 & 3,0 \\
\hline
\end{tabular}

Fonte: Relatório Oficial do fluxo de IED da China (2003-2009).

No período 2003 a 2008, o fluxo de investimento direto da China para a África foi relativamente pequeno, porém com um crescimento rápido e contínuo. Todavia, atingido pela crise financeira, este fluxo sofreu uma queda acentuada em 2009. A África do Sul e a Nigéria são os países com maior investimento direto da China, cujo estoque de investimentos atingiu 35,7\% dos estoques totais de investimentos chineses na África em 2009. De modo geral, a escala de investimentos da China na África é pequeno, de forma que os benefícios econômicos não são óbvios.

Quadro 6 - O volume de contratação de projetos, cooperação de mão-de-obra e consultoria de projetos e suas proporções

\begin{tabular}{|c|c|c|}
\hline ANo & Volume (BILHÕES U\$ & ProporçÃo (\%) \\
\hline 2005 & 6,27 & 23,4 \\
\hline 2006 & 9,59 & 26,8 \\
\hline 2007 & 12,69 & 26,5 \\
\hline 2008 & 20,10 & 30,9 \\
\hline 2009 & 28,44 & 32,8 \\
\hline
\end{tabular}

Fonte: China Statistical Yearbook (2005-2010).

De 2005 a 2009, a taxa de crescimento anual do volume de contratação de projetos, cooperação de mão-de-obra e consultoria de projetos da China chegou a 46\%, superior à sua taxa de cooperação econômica estrangeira, que foi de 37,5\% durante o mesmo período. Conforme mostram os dados, a proporção da cooperação econômica sino-africana vem aumentando anualmente, ficando atrás apenas da Ásia. A África se tornou o segundo maior mercado 
estrangeiro de contratação de projetos chineses, com sua cooperação não-laboral crescendo regularmente.

\section{REFLEXÕES SOBRE A EXPANSÃO ECONÔMICA CHINESA NA AMÉRICA LATINA E ÁFRICA}

A China logrou visível êxito em sua estratégia de "saída", ao fazer completo uso de recursos estrangeiros e mercados. Neste âmbito, sua competitividade internacional melhorou enormemente. Enquanto isso, alguns países ocidentais que, por bastante tempo, implementam políticas colonizadoras em relação à África e AL estão tão preocupados com a emergência pacífica da China que estão rotulando sua expansão econômica no estrangeiro como "exploração de recursos" e "novo colonialismo". A essência da expansão econômica chinesa na AL e África é tomar como base o respeito e a confiança política mútuas para proporcionar benefícios recíprocos e aprofundar a cooperação e o desenvolvimento econômico de ambos.

\subsection{A expansão econômica chinesa na AL e África deve suprir as necessidades da divisão internacional do trabalho e da participação na globalização econômica}

Para suprir as necessidades de continuar melhorando a utilização de recursos, participando da economia internacional, da cooperação tecnológica e da competição em campos mais amplos e em um nível superior, a China acelera sua integração na globalização econômica e faz pleno uso dos mercados e recursos domésticos e estrangeiros. Também é inevitável a opção chinesa por realizar o ajuste estrutural estratégico do modo de desenvolvimento econômico e a otimização da estrutura industrial.

A China é o maior consumidor mundial e o maior importador de diversos recursos e produtos energéticos, com a dependência da importação de minério de ferro e petróleo bruto atingindo 70\% e 54\%, respectivamente. Como a AL e a África são ricos em recursos minerais e energéticos, as importações e investimentos podem compensar efetivamente a lacuna energética no desenvolvimento econômico chinês. 


\subsection{O objetivo da expansão econômica chinesa na AL e na África é sempre alcançar benefícios mútuos e um cenário no qual ambos ganhem}

A China persegue firmemente a estratégia do benefício mútuo, um cenário no qual todos atinjam seus objetivos. Para tal, aumenta constantemente os interesses complementares, focando no desenvolvimento da economia nacional mediante uso de recursos e mercados, enquanto se compromete com o bem-estar dos povos ao redor do mundo, especialmente aqueles de países em desenvolvimento. Como resultado, o desenvolvimento chinês exerce incalculável impacto na modernização de países em desenvolvimento.

Até certo ponto a cooperação econômica e comercial sino-latino-americana tem suprido as necessidades do desenvolvimento econômico latino-americano por produtos, capitais e tecnologias. Além disto, graças ao crescimento econômico chinês, a AL lucrou entre U\$ 42 bilhões e U\$ 75 bilhões de 2000 a 2008.

Na cooperação econômica e comercial sino-africana, apenas o comércio entre China e África contribuiu com mais de $20 \%$ do crescimento econômico africano. Os projetos chineses contratados na África estão concentrados principalmente em infraestrutura, onde um grande número de projetos premium, benéficos às vidas das populações, tem sido construído. Em termos de cooperação laboral, a China tem treinado um grande número de técnicos e profissionais em geral para a África. Esta iniciativa contribui para estabelecer uma boa base de recursos humanos para o desenvolvimento econômico e social africano. Além disto, a China isentou 35 países africanos dos seus débitos de 20 bilhões de yuans entre 2000 e 2009, na tentativa de ajudar o desenvolvimento econômico do continente.

\section{AS CONSEQUÊNCIAS GLOBAIS DA EXPANSÃO ECONÔMICA ESTRANGEIRA DA CHINA}

Como uma nação que sempre sofreu com a agressão colonial, os chineses sabem respeitar a soberania e a liberdade de outros países e ajudar povos de países subdesenvolvidos. Como um gigante emergente responsável, a China frequentemente exerce sua influência e sua vantagem de capital na construção social e 
econômica de países subdesenvolvidos na África e AL. Durante sua expansão econômica para o exterior, a China não exporta nem sua pobreza nem sua ideologia. Contudo, sua expansão econômica no estrangeiro pode ajudar a aumentar sua própria força e restringir a ampliação da hegemonia, de modo a ajudar países do Terceiro Mundo a efetivar sua modernização.

\subsection{Impactos em países em desenvolvimento}

Diferentemente do controle político e a pilhagem econômica de países em desenvolvimento por países desenvolvidos como os EUA, a China tem ajudado a melhorar constantemente o desenvolvimento das economias nacionais de países em desenvolvimento e o direito dos seus povos de escolher de maneira independente a rota de desenvolvimento através do livre comércio, ajuda econômica, educação e treinamento. Tudo isso tem melhorado efetivamente o status internacional de países em desenvolvimento e o padrão de vida das suas populações. Conforme evidenciado, aumentou enormemente suas reservas tecnológicas e de talentos e estabeleceu uma base sólida para seu desenvolvimento em longo prazo.

\subsection{Impactos em países ocidentais desenvolvidos}

A cooperação econômica e comercial de benefícios mútuos da China com a África e a AL mudou completamente as regras da pilhagem colonial sobre países africanos por países ocidentais. Ademais, balançou as bases da imposição ideológica de países do Ocidente e também furou o bloqueio econômico e tecnológico da China por parte de referidos países, o que lhe possibilitou obter materiais estratégicos altamente sensíveis a estes países. Além disto, a expansão econômica da China no exterior vai, definitivamente, entrar em conflito com os interesses dos países desenvolvidos na AL e na África. Deste modo influenciará os impactos políticos e econômicos de países desenvolvidos sobre países do Terceiro Mundo e enfraquecerá sua hegemonia tradicional. Enquanto isso, por conta da melhoria no status internacional da China, países ocidentais também estão preocupados com o declínio da sua competitividade. 


\subsection{Impactos na China}

A cooperação econômica da China com regiões asiáticas, africanas e latino-americanas tem consolidado ainda mais a amizade tradicional das populações, promovido a confiança política mútua e trabalhado para alcançar um cenário de benefícios para todos os envolvidos. Enquanto isso, o uso de recursos e energia estrangeiros tem diminuído efetivamente a pressão sobre o suprimento doméstico, garantindo, assim, a segurança econômica e energética da China. Neste prisma, o comércio bilateral e a cooperação econômica têm promovido as vantagens complementares e melhorado a estrutura industrial chinesa, de modo que os recursos possam ser alocados de maneira razoável. Além do mais, os acordos de swap de moeda entre a China e alguns países em desenvolvimento são vantajosos para o salvamento da reserva de moeda estrangeira e a redução da dependência no dólar estadunidense e, assim, melhoram a regionalização do renminbi ${ }^{1}$ e o ambiente de segurança financeira internacional.

\subsection{Impactos na relação sino-estadunidense}

A China logrou ultrapassar o Japão e se tornar a segunda maior economia mundial, com crescimento óbvio em sua expansão econômica no exterior e em seu status internacional. Com vistas a manter sua hegemonia global, os EUA tentaram marginalizar e conter o desenvolvimento econômico da China de diversas formas, tais como a investigação antidumping e antissubsídios de longo prazo nas importações da China para os EUA, impedindo a aquisição de negócios estadunidenses por companhias chinesas e a exportação por empresas estadunidenses de produtos de alta tecnologia para a China. Por conta das diferenças na ideologia e no sistema social, e com a emergência da China, o confronto político entre China e EUA e a provocação política pelos EUA vão aumentar de maneira constante. Além disto, as relações militares sino-estadunidenses têm frequentemente atingido seu ponto mais baixo, em face da emergência de diversos assuntos sensíveis. A cooperação pacífica entre China e EUA trará benefícios, enquanto

1 Nota do tradutor: Unidade de moeda chinesa. 
o conflito apenas traz perdas para ambos os lados. Assim, estabelecer relações políticas, econômicas e militares próximas não favorece apenas o desenvolvimento econômico de ambos os países, mas também a paz e a estabilidade mundiais.

Tradução: Camila Alves da Costa

\section{REFERÊNCIAS}

HANDI, Wu. Research on China's direct investment in Latin America since the new century. Journal of Graduate School of Chinese Academy of Social Sciences, v. 2, 2011.

HONGMING, Zhang. The cooperation of China and Africa: "neocolonialism" or equality and mutual benefit. Study Monthly, v. 23, 2006.

SHAOZHONG, Cui. Post-crisis monetary policies of the US and the Enlightenment for Sino-African Economic Cooperation. Innovation, v. 3, 2011.

XIANSHU, Yin. Study on the current situation and developing tendency of China's outflow FDI. Journal of Central University of Finance \& Economics, 2009(4).

XIAOQIN, He. The development and objectives of the "going global" strategy in China's enterprises. World Economy Study, v. 10, 2008. 